\title{
Protein Misfolding and Retinal Degeneration
}

\author{
Radouil Tzekov, Linda Stein, and Shalesh Kaushal \\ Department of Ophthalmology, University of Massachusetts Medical School, Worcester, Massachusetts 01655 \\ Correspondence: Shalesh.Kaushal@umassmemorial.org
}

The retina is a highly complex and specialized organ that performs preliminary analysis of visual information. Composed of highly metabolically active tissue, the retina requires a precise and well-balanced means of maintaining its functional activity during extended periods of time. Maintenance and regulation of a vast array of different structural and functional proteins is required for normal function of the retina. This process is referred to as protein homeostasis and involves a variety of activities, including protein synthesis, folding, transport, degradation, elimination, and recycling. Deregulation of any of these activities can lead to malfunctioning of the retina, from subtle subclinical signs to severe retinal degenerative diseases leading to blindness. Examples of retinal degenerative diseases caused by disruption of protein homeostasis include retinitis pigmentosa and Stargardt's disease. A detailed discussion of the role of disruption in protein homeostasis in these and other retinal diseases is presented, followed by examples of some existing and potential treatments.

$T^{\mathrm{h}}$ he vertebrate retina is a highly complex and specialized organ, which captures light from the surroundings and performs preliminary analysis of visual information. To be effective, the retina must function reliably within a very wide range of illumination and contrast environments, from almost complete darkness to an extremely bright light level, close to the level of retinal light damage. The high demands imposed by illumination range and complex visual environments require synchronization and coordination in the functioning of various retinal cells, including retinal neurons, glial cells, and adjacent pigment epithelial cells. Such coordination would be impossible without the existence of a precise and well-balanced way of maintaining the functional activity of the various cell types during extended periods of time.

One of the key aspects of this functional mechanism involves maintaining and regulating the presence and activity of a vast array of different structural and functional proteins required for the normal functioning of the retina. This mechanism can generally be defined as "protein homeostasis" and involves a variety of activities, including control of protein synthesis, protein folding, protein transport and protein degradation, and elimination and recycling (Hebert and Molinari 2007). The focus of this article will be the role of protein folding as a major part of maintaining protein homeostasis in the normal and diseased retina. Inherited alterations of the protein structure can have

Editors: Richard I. Morimoto, Dennis Selkoe, and Jeff Kelly

Additional Perspectives on Protein Homeostasis available at www.cshperspectives.org

Copyright (C) 2011 Cold Spring Harbor Laboratory Press; all rights reserved; doi: 10.1101/cshperspect.a007492

Cite this article as Cold Spring Harb Perspect Biol 2011;3:a007492 
R. Tzekov et al.

varying effects on the normal morphology and functioning of the retina. To date, defects of more than 150 genes synthesizing retinal proteins have been identified as causes for retinal degenerative diseases (RetNet [the Retinal Network] http://www.sph.uth.tmc.edu/RetNet/).

The structure of the mammalian retina can generally be subdivided into two parts: the outer retina, including the photoreceptors and the underlying retinal pigment epithelium (RPE), and the inner retina, including various neuronal types and glial cells (Fig. 1). Metabolic activity is higher in the outer compared to the inner retina, in part because of the fact that the photoreceptors need to renew the content of their outer segments (rods much more intensively than cones) through shedding of the tips and phagocytosis by the RPE cells. As this process is quite intensive $(\sim 10 \%$ of the outer segment content per day in rods) (Young 1971), maintaining this ability requires a high level of protein synthesis, correct folding, and transport of various proteins. When any of these processes are affected, there could be profound consequences for normal functioning of the outer retina, and if the disturbances are severe, a degenerative process within the tissue will start and spread. The sequence of events following the accumulation of unfolded or misfolded protein is defined as the unfolded protein response.

\section{UNFOLDED PROTEIN RESPONSE (UPR)}

The UPR is a cellular stress response related to accumulation of unfolded or misfolded proteins in the lumen of the endoplasmic reticulum (ER) and conserved between mammalian species. If the UPR is unable to restore normal function of the cell (by halting protein translation and activating the signaling pathways that lead to increased production of molecular chaperones involved in protein folding), the UPR initiates apoptosis (Shroder and Kaufman 2005; Szegezdi et al. 2006).

There are three branches of the UPR mediated by different factors: IRE1, PERK, and ATF6. These factors promote cell survival by reducing misfolded protein levels (Bernales et al. 2006). Alternatively, UPR signaling promotes apoptotic cell death if ER stress is not alleviated. How the UPR integrates its cytoprotective and proapoptotic outputs to select between life or death of cells is unknown. Some studies have shown that IRE1 and ATF6 activities were attenuated by persistent ER stress in human cells. By contrast, PERK signaling, including translational inhibition and
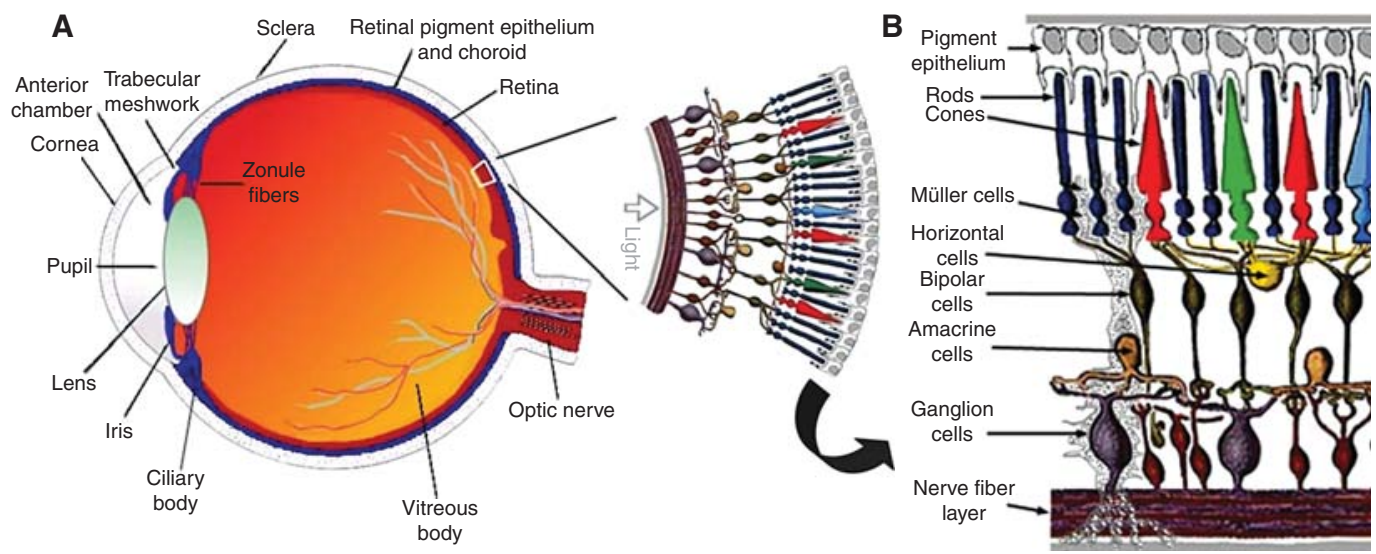

Figure 1. Structure and function of the eye. (A) Vertical sagittal section of the adult human eye, and schematic of human peripheral retina (Panel adapted from Webvision and reprinted with permission from webvision@hsc. utah.edu (C) 2011.) (B) Schematic enlargement of retinal cells. (Panel adapted from Roy et al. [2010] and reprinted, with permission, from Mary Ann Liebert, Inc. (C) 2010.) 
proapoptotic transcription regulator $\mathrm{CHOP}$ induction, was maintained. When IRE1 activity was sustained artificially, cell survival was enhanced, suggesting a causal link between the duration of UPR branch signaling and life or death of cells after ER stress (Lin et al. 2007).

\section{UPR IN PHOTORECEPTORS}

\section{Rhodopsin Mutations}

Rhodopsin is the most abundant protein in photoreceptors, $\sim 30 \%$ of the entire proteome of photoreceptors and comprising $\sim 90 \%$ of all proteins in the outer segment region of photoreceptors (Hargrave 2001). Rhodopsin has two parts: an opsin molecule and a chromophore, 11-cis-retinal, which is bound to it. The opsin molecule is a $40-\mathrm{KDa}$ protein, which is composed of 348 amino acids (human) and has seven transmembrane domains (Fig. 2). Of note, rhodopsin is expressed in rod cells, whereas cone cells express slightly different kinds of opsins, depending on their spectral characteristics (Nathans et al. 1989). Rhodopsin synthesis occurs at the ER of the inner segments of photoreceptors and undergoes multiple posttranslational modifications (Kaushal et al. 1994; Krebs et al. 2004) until the final form becomes part of the discs in the outer segments.

If the genetic mechanisms ensuring that rod photoreceptors function normally are affected, and the photoreceptors cease functioning properly and start degenerating, this process is usually defined as rod-cone degeneration, or retinitis pigmentosa (RP). By the mode of inheritance, RP can be defined as autosomal dominant (adRP), autosomal recessive (arRP), or X-linked (xlRP). Rhodopsin mutations are the most common cause of RP and account for 25\%-30\% of adRP (Sohocki et al. 2001). The majority of adRP-linked rhodopsin mutations lead to misfolding of the rhodopsin molecule (Kaushal and Khorana 1994; Kaushal et al. 1994).

One rhodopsin mutation deserves particular attention. It is called Pro23His, or $\mathrm{P} 23 \mathrm{H}$, and corresponds to a proline-to-histidine substitution near the amino terminus of rhodopsin; it is the most frequent mutation among
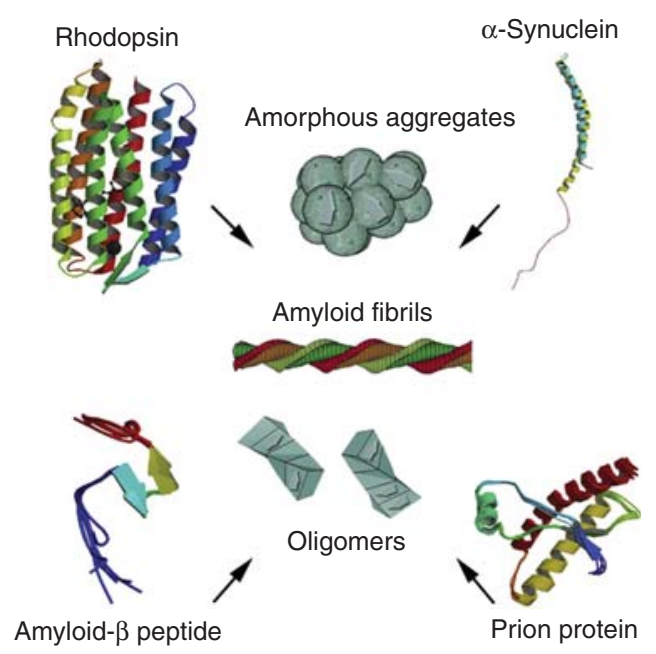

Figure 2. Misfolding of rhodopsin protein in the eye can lead to mutations and serious vision diseases. Protein homeostasis mechanisms play a large role in maintaining properly folded rhodopsin. The misfolding and accumulation of $\alpha$-synuclein plays a major role in the pathogenesis of Parkinson's disease. Amyloid- $\beta$ protein may be involved in the development of glaucomatous retinal ganglion cell apoptosis, and amyloid- $\beta$ deposits are considered to be the fundamental cause of Alzheimer disease. Prion proteins can become amyloidogenic as a result of protein-mediated transformation. When these types of proteins aggregate, they can form amyloid fibrils, amorphous aggregates, or oligomers. (Figure adapted from Surgechev and Surgechev [2010] and reprinted, with permission, from Elsevier (C) 2010.)

patients with adRP in North America (Berson et al. 1991). The amino-terminal domain normally positions and binds 11-cis-retinal to form fully functional rhodopsin. Mutations in this region, such as the $\mathrm{P} 23 \mathrm{H}$ substitution, could lead to misfolding and hence impair binding of the 11-cis-retinal chromophore (Kaushal and Khorana 1994; Kaushal et al. 1994; Noorwez et al. 2003, 2004; Tam and Moritz 2006). This is likely to hold true for additional adRP-linked mutant rhodopsins as well.

Recent studies show that the time course of the BiP protein mRNA decline and the proapoptotic protein $\mathrm{CHOP}$ mRNA rise tightly match the rate of retinal degeneration in $\mathrm{P} 23 \mathrm{H}$ rhodopsin transgenic animals. Furthermore, the changes in BiP and CHOP mRNA levels in 
R. Tzekov et al.

retinas expressing misfolded rhodopsin mirrored the results seen in cell culture after prolonged ER stress. Thus, an attenuation of cytoprotective UPR output, coupled with sustained CHOP production, contributed to cell death (Lin et al. 2007). The levels of mutant misfolded rhodopsin, but not those of normal rhodopsin, appear to control disease development and apoptosis in retinal photoreceptor cells of transgenic S334ter rats (Shinohara et al. 2008).

Another recent study shows the role of quality control systems in regulating the correct folding of rhodopsin. The lectin chaperone calnexin $(\mathrm{Cnx})$ is important for quality control of glycoproteins, and it was shown that Cnx preferentially associates with misfolded mutant opsins associated with retinitis pigmentosa. Furthermore, the overexpression of Cnx leads to an increased accumulation of misfolded $\mathrm{P} 23 \mathrm{H}$ opsin but not the correctly folded protein. Increased levels of $\mathrm{Cnx}$ in the presence of the pharmacological chaperone 11-cis-retinal increase the folding efficiency and result in an increase in correct folding of mutant rhodopsin. These results show that misfolded rather than correctly folded rhodopsin is a substrate for Cnx and that the interaction between Cnx and mutant, misfolded rhodopsin can be targeted to increase the yield of correctly folded protein (Noorwez et al. 2009).

It is also possible that down-regulation of $\mathrm{BiP}$ contributes to the photoreceptor degeneration occurring in $\mathrm{P} 23 \mathrm{H}$ mutant retinas. This was tested by subretinal delivery of adenovirus vector expressing $\mathrm{BiP}$ in $\mathrm{P} 23 \mathrm{H}$ transgenic rats (Gorbatuk et al. 2010). This test led to reduction in CHOP and photoreceptor apoptosis and to a sustained increase in electroretinogram (ERG) amplitudes. Thus, the preservation of photoreceptor function resulting from elevated levels of $\mathrm{BiP}$ could be due mostly to suppression of apoptosis rather than to a promotion of rhodopsin folding.

\section{Mutations in Other Photoreceptor Proteins}

\section{Mutations in Phosphodiesterase 6}

Phosphodiesterase 6 (PDE6) is a multisubunit enzyme that plays a major role in visual function by hydrolysing cGMP in response to a light stimulus. The phenotype of mice carrying a mutation leading to a defect in the $\beta$-subunit of PDE6, the rd1 mouse, involves profound reduction of the protein and severe retinal degeneration (Bowes et al. 1990). Photoreceptor apoptosis in the rd1 mouse was detected by TUNEL. Protein expressions of ER stress sensors (BiP, caspase-12, and others) indicated that the protein expressions of ER stress sensors were up-regulated in a time-dependent manner. The up-regulation of these proteins coincided with or preceded photoreceptor apoptosis. This indicates activation of multiple UPR signaling pathways at ages that precede frank photoreceptor cell death (Yang et al. 2007).

\section{Mutations in ELOVL4}

The ELOVL4 gene encodes a membrane-bound 314 amino acid, $36.8 \mathrm{kDa}$ protein, which is a member of the ELO family and a photoreceptorspecific component of the fatty acid elongation system residing on the endoplasmic reticulum. Both rod and cone photoreceptor inner segments express high levels of ELOVL4 (Zhang et al. 2001). Mutations in the ELOVL4 gene lead to autosomal dominant juvenile onset macular dystrophy (Zhang et al. 2001). Transgenic mice expressing a mutant form of human ELOVL4 showed accumulation by the RPE of undigested phagosomes and lipofuscin, followed by RPE atrophy (Karan et al. 2005a). Mutant ELOVL4 also was mislocalized and formed aggregates; when cotransfected with wild-type ELOVL4, the mutants bound to and sequestered the wild-type protein into the aggregates. Expression of ELOVL4 mutants also induced UPR as evidenced by $\mathrm{BiP}$ and $\mathrm{CHOP}$ expression, raising the possibility that these signaling pathways link ELOVL4 misfolding and aggregation in the ER with photoreceptor cell fate (Karan et al. 2004, 2005b).

\section{Mutations in ABCA4}

ABCA4 is a $250 \mathrm{kDa}$ single-chain ABC transporter protein localized to the disk margins of vertebrate photoreceptor outer segments. Its primary function is to transport all-trans retinal and a phosphlipid (N-retinylidene-PE) 
across the disc membrane in the outer segments of the photoreceptors (Weng et al. 1999). Alteration of the function of this gene in knockout mice leads to accumulation of lipofuscin granules in the RPE (Weng et al. 1999; Mata et al. 2001), which indicates a similarity with human diseases such as Stargard's disease and agerelated macular degeneration. Indeed, mutations in the ABCA4 gene have been identified in large number of patients with Stargard's disease (Allikmets et al. 1997) and in some patients with cone-rod dystrophy and autosomal recessive retinitis pigmentosa (Cremers et al. 1998). In vitro studies of missense mutations were analyzed functionally in the photoreceptors of Xenopus laevis tadpoles, which revealed mislocalization of ABCA4 protein. These mutations cause retention of ABCA4 in the photoreceptor inner segment, likely by impairing correct folding, resulting in the total absence of physiologic protein function (Wiszniewski et al. 2005).

\section{Mutations in Retinoschisin}

Retinoschisin is a $24-\mathrm{kDa}$ protein that is secreted from photoreceptor and bipolar cells and functions as a cell adhesion protein to maintain the cellular organization of the retina. Defects in the gene lead to X-linked juvenile retinoschisis, a recessively inherited vitreoretinal degeneration characterized by macular pathology and intraretinal splitting of the retina (Sauer et al. 1997). Biochemical studies clearly showed that misfolding of one of the protein domains, defective disulfide-linked subunit assembly, and inability of retinoschisin to insert into the endoplasmic reticulum membrane as part of the protein secretion process are three primary mechanisms responsible for loss in the function of retinoschisin as a cell adhesion protein and the pathogenesis of X-linked juvenile retinoschisis (Wu and Molday 2003).

\section{UPR IN RPE CELLS}

The RPE provides critical support for the normal functioning of photoreceptors, and any alteration in RPE function could have serious consequences for the integrity and proper function of the overlying retina structures. Thus, recently, based on studies in Xenopus laevis, it was hypothesized that in the absence of the RPE, oxidative stress initiates an unfolded protein response. Subsequently, down-regulation of several candidate Müller glial cell proteins may explain the inability of photoreceptors to properly fold their outer segment membranes (Wang et al. 2009).

Very little is currently known about the effects of misfolded protein accumulation in $\mathrm{RPE}$ as a trigger and cause of retinal degeneration. One of the very few examples currently available is the role of fibulin-3 (also known as EFEMP1) alterations in macular degeneration. A missense mutation in that protein, R345W, causes Malattia Leventinese, an autosomal dominant macular degeneration (Stone et al. 1999). Additionally, in a knockin mouse with the same mutation, basal laminar deposits in the Bruch's membrane, a hallmark of human macular degeneration, are histologically identified as the earliest change in the eyes (Fu et al. 2007; Marmorstein et al. 2007). Moreover, in studies in ARPE-19 cells, R345W was poorly secreted and accumulated in the ER, leading to UPR activation (Roybal et al. 2005).

Another protein expressed in RPE cells is bestrophin 1. It is a protein localized on the basolateral plasma membrane of the retinal pigment epithelium (Marmostein et al. 2000). Mutations in this protein cause a variety of retinal diseases, including best vitelliform macular dystrophy, autosomal dominant vitreoretinochoroidopathy, and autosomal recessive bestrophinopathy (Burgess et al. 2008). It has been hypothesized that mutations in the bestrophin 1 gene lead to defective membrane integration and protein misfolding leading to UPR (Milenkovic et al. 2007).

\section{ROLE OF MISFOLDED PROTEINS IN DISEASES OF THE INNER RETINA}

Only a few recent studies provide an insight into this emerging area of research. Misfolded proteins are implicated in retinal ganglion cell (RGC) death. Experimental studies for glaucoma support the involvement of amyloid 
R. Tzekov et al.

$\beta$-protein $(\mathrm{A} \beta)$ in the development of glaucomatous RGC apoptosis. Furthermore, it was shown that exogenous $A \beta$ peptide induces significant RGC apoptosis in vivo in a dose- and time-dependent manner. Three different agents were also tested targeting $A \beta$ formation: a $\beta$-secretase inhibitor, an anti-A $\beta$ antibody, and Congo red. All three treatments altered the profile of RGC apoptosis, but the anti-A $\beta$ antibody appeared the most effective, with prolonged effects after a single application up to 16 weeks after IOP elevation (Guo et al. 2007). These findings were confirmed by a recent study showing that endoplasmic reticulum stress induced RGC death in chronic ocular hypertension (Doh et al. 2010).

\section{MILD UPR RESPONSE MAY BE PROTECTIVE IN THE CONTEXT OF RETINAL DEGENERATIONS}

Recent studies indicate that in Drosophila, mutations in the ER-resident chaperone (NinaA) lead to mild ER stress, protecting photoreceptor neurons from various death stimuli. In addition, Drosophila S2 cultured cells, when preexposed to mild ER stress, are protected from $\mathrm{H}_{2} \mathrm{O}_{2}$, cycloheximide- or ultraviolet-induced cell death. A specific ER-mediated signal promotes antioxidant defenses and inhibits caspase-dependent cell death. These findings could indicate that an immediate consequence of the UPR involves not only limiting the accumulation of misfolded proteins but also protecting tissues from harmful exogenous stresses (Mendes et al. 2009). It remains to be determined whether or not these findings apply to the mammalian retina.

\section{CLINICAL MANIFESTATIONS OF PROTEIN MISFOLDING IN THE RETINA}

\section{Retinitis Pigmentosa}

As stated above, rhodopsin mutations lead to cases of retinitis pigmentosa, which can be inherited in an autosomal dominant (adRP), autosomal-recessive (arRP), or X-linked (xlRP) manner. Rhodopsin mutations can also lead to congenital stationary night blindness and other diseases (RetNet [the Retinal Network] http:// www.sph.uth.tmc.edu/RetNet/). In addition to rhodopsin mutations, another 16 genes have been identified that cause adRP, and another 24 genes have been identified that cause arRP. Moreover, two genes have been identified as causing xlRP (RetNet [the Retinal Network] http://www.sph.uth.tmc.edu/RetNet/). Thus, there is a great deal of genotypic variation causing RP, which translates into great phenotypic variation, too. The phenotypic heterogeneity presents considerable challenges for the clinician, as many forms do not have a typical appearance. What is a "typical" appearance? The most often described RP fundus includes attenuated retinal vessels, bone spicule, intraretinal pigmentation, mottling and granularity of the retinal pigment epithelium, and optic nerve head pallor. The most consistent diagnostic sign of the disease is a larger deficit in the rod system compared to the cone system as determined by ERG. The progression of the disease is relatively slow, but can vary significantly across different genotypes (Birch 1999). A number of treatments for RP have been proposed and tested in animal models and clinical studies; however, the disease remains incurable.

\section{Stargardt's Disease}

Stargardt's disease (and its variant, fundus flavimaculatus) is an inherited juvenile macular degeneration characterized by bilateral and symmetrical fleck lesions of various sizes and shapes confined to the retinal pigment epithelium. The disease can be inherited either in an autosomal recessive manner (STGD1), which is the more prevalent form, or in an autosomal dominant manner (STGD3 and STGD4). The recessive form can be caused by mutations in the ABCA4 gene (Allikmets et al. 1997), whereas the dominant form can be caused by mutations in the ELOVL4 gene (Zhang et al. 2001) or the Prominin-1 gene (Michaelides et al. 2003; Yang et al. 2008). The maculopathy leads to extensive central vision loss and prominent development of central lesions. As with RP, no current treatment is available for the disease. 
Retinal Involvement in Systemic Protein Misfolding Diseases

\section{Alzheimer Disease}

Alzheimer disease is the most common form of dementia and is an age-related, incurable degenerative disease. Currently, the dominant hypothesis is that amyloid $\beta(A \beta)$ deposits are the fundamental cause of the disease (Hardy and Allsop 1991). As mentioned above (in the section Role of Misfolded Proteins in Diseases of the Inner Retina), $A \beta$ accumulation was connected recently with retinal ganglion cell death in the context of glaucoma. Similarly, some reports have found an association between ganglion cell loss and advanced forms of Alzheimer disease (Blanks et al. 1996), whereas others have not (Curcio and Drucker 1993). This controversy extends also to results from visual function testing, such as pattern electroretinography, in which some reports find no association with the disease (Strenn et al. 1991; Prager et al. 1993), whereas others find association either with amplitude (Katz et al. 1989; Trick et al. 1989) or timing parameters (Parisi et al. 2001). More recent studies, employing advanced technology, seem to confirm both morphological (Paquet et al. 2007) and functional retinal deficit in the disease (Startucci et al. 2010).

\section{Parkinson's Disease}

Parkinson's disease is the second most common neurodegenerative disorder in the developed world. It is believed that the misfolding and accumulation of a protein, $\alpha$-synuclein, plays a significant role in its pathogenesis (Schultz 2007). Although direct degenerative changes have not been reported, various alterations in vision function have been documented (Archibald et al. 2009), including decline in visual acuity, contrast sensitivity, color vision, motion perception, and bioelectrical activity as measured by flash and pattern electroretinography and other types of measurements. Further studies are necessary to clarify the role of $\alpha$-synuclein and better characterize the correlation between $\alpha$-synuclein misfolding and accumulation in the retina and the extent of visual dysfunction observed.

\section{THERAPEUTIC STRATEGIES FOR CORRECTION OF PROTEIN MISFOLDING IN RETINAL DEGENERATIONS}

The variety of genotypic backgrounds and phenotypic expressions makes treatment of retinal degenerations challenging, and no universal or effective treatment currently exists. Different therapeutic strategies have been proposed over the years, which can generally be classified into three major groups: pharmacological rescue, gene therapy, and combination therapy. Pharmacological rescue is a broad approach involving different strategies such as ribosomes, neurotrophic factors, and pharmacological chaperones (Mendes et al. 2005). Of these three possibilities, use of pharmacological chaperones remains the most promising approach.

Pharmacological chaperones are small molecules that enter the cells and serve as molecular scaffolding that allows otherwise misfolded mutant proteins to fold and route correctly within the cell. Within the context of photoreceptors, several molecules have been identified as having pharmacological chaperone properties. Studies in Xenopus showed that 11-cisretinal can be a successful pharmacological chaperone in vivo for the $\mathrm{P} 23 \mathrm{H}$ mutation (Moritz and Tam 2010). Furthermore, 11-cis-retinal has been used in vitro to assess its potential for pharmacologic rescue for six rhodopsin pathogenic mutations and nonpathogenic variants (Krebs et al. 2010). The results indicate that only mutations $(\mathrm{P} 23 \mathrm{H}$ and $\mathrm{T} 17 \mathrm{M})$ were rescued in a significant way. This may explain the modest clinical efficacy of vitamin A therapy when applied as treatment in a broad range of RP mutations (Berson et al. 1993). Significant efforts are currently underway to identify chaperones for nonrhodopsin mutations or more broadly acting chaperones, which could be effective in a wider range of rhodopsin mutations. Some pilot clinical observations indicate that some recognized and widely used histone deacetylase inhibitors, which could also act as pharmacological chaperones (such as valproic acid), 
R. Tzekov et al.

could have a positive effect on the course of retinal degeneration in RP (Clemson et al. 2011).

Gene therapy holds promise for the treatment of a wide variety of retinal degenerations, although the mechanisms for delivering the nondefective gene to replace the defective one and protecting the retina would vary for different forms of the disease, and the results would depend on the precise mechanism affected. An example is a study in which $\mathrm{P} 23 \mathrm{H}$ and S334ter rhodopsin transgenic rat models of RP were used to test the neuroprotective effects of adeno-associated viruses carrying the X-linked inhibitor of apoptosis (xlAP). xlAP treatment preserved outer nuclear layer (ONL) morphology in both $\mathrm{P} 23 \mathrm{H}$ and S334ter animals. However, statistically significant functional protection as measured by ERG was observed only for P23H animals (Leonard et al. 2007). Another approach similar to gene therapy could be the use of substances that inhibit RNA synthesis (such as siRNA) of proteins from defective genes. Like gene delivery, this work is in very early stages of development.

Although both pharmacological rescue and gene therapy hold some promise for retinal degenerative disease treatment, either strategy by itself would probably have limited success. Therefore, combination therapy, including these two approaches and/or some other treatment options, such as transcorneal electrical stimulation of the retina (Morimoto et al. 2007), carries the most promise.

\section{CONCLUDING REMARKS}

Many retinal disorders can be considered protein conformational diseases. Retinal disorders often have common features and, in most cases, have significant negative impacts on retinal structure and function. Studies of the mechanisms by which disturbances in protein homeostasis impact the normal condition of the retina have resulted in considerable advances in the past decade, but more work is necessary to assess the potential for correcting disturbances in protein homeostasis with various therapeutic approaches. Our knowledge is continuously expanding in this area, and testing and introduction of new treatment modalities in the clinic is imminent. The hope is that future multimodal therapies could be tailored to individual patients based on their genotype and phenotype, which would increase greatly the chances of halting the course of retinal disease progression and ultimately lead to long-term restoration of visual function.

\section{REFERENCES}

Allikmets R, Singh N, Sun H, Shroyer NF, Hutchinson A, Chidambaram A, Gerrard B, Baird L, Stauffer D, Peiffer A, et al. 1997. A photoreceptor cell-specific ATP-binding transporter gene (ABCR) is mutated in recessive Stargardt macular dystrophy. Nat Genet 15: 236-246.

Archibald NK, Clarke MP, Mosimann UP, Burn DJ. 2009. The retina in Parkinson's disease. Brain 132: 1128-1145.

Bernales S, Papa FR, Walter P. 2006. Intracellular signaling by the unfolded protein response. Annu Rev Cell Dev Biol 22: 487-508.

Berson EL, Rosner B, Sandberg MA, Dryja TP. 1991. Ocular findings in patients with autosomal dominant retinitis pigmentosa and a rhodopsin gene defect (Pro-23-His). Arch Ophthalmol 109: 92-101.

Berson EL, Rosner B, Sandberg MA, Hayes KC, Nicholson BW, Weigel-DiFranco C, Willett W. 1993. A randomized trial of vitamin A and vitamin E supplementation for retinitis pigmentosa. Arch Ophthalmol 111: 761-772.

Birch DG, Anderson JL, Fish GE. 1999. Yearly rates of rod and cone functional loss in retinitis pigmentosa and cone-rod dystrophy. Ophthalmology 106: 258-268.

Blanks JC, Torigoe Y, Hinton DR, Blanks RH. 1996. Retinal pathology in Alzheimer's disease. I. Ganglion cell loss in foveal/parafoveal retina. Neurobiol Aging 17: 377-384.

Bowes C, Li T, Danciger M, Baxter LC, Applebury ML, Farber DB. 1990. Retinal degeneration in the rd mouse is caused by a defect in the $\beta$ subunit of rod cGMPphosphodiesterase. Nature 347: 677-680.

Burgess R, Millar ID, Leroy BP, Urquhart JE, Fearon IM, De Baere E, Brown PD, Robson AG, Wright GA, Kestelyn P, et al. 2008. Biallelic mutation of BEST1 causes a distinct retinopathy in humans. Am J Hum Genet 82: 19-31.

Clemson CM, Tzekov R, Krebs M, Checchi JM, Bigelow C, Kaushal S. 2011. Therapeutic potential of valproic acid for retinitis pigmentosa. Br J Ophthalmol 95: 89-93.

Cremers FP, van de Pol DJ, van Driel M, den Hollander AI, van Haren FJ, Knoers NV, Tijmes N, Bergen AA, Rohrschneider K, Blankenagel A, et al. 1998. Autosomal recessive retinitis pigmentosa and cone-rod dystrophy caused by splice site mutations in the Stargardt's disease gene ABCR. Hum Mol Genet 7: 355-362.

Curcio CA, Drucker DN. 1993. Retinal ganglion cells in Alzheimer's disease and aging. Ann Neurol 33: 248-257.

Doh SH, Kim JH, Lee KM, Park HY, Park CK. 2010. Retinal ganglion cell death induced by endoplasmic reticulum stress in a chronic glaucoma model. Brain Res 1308: $158-166$. 
Fu L, Garland D, Yang Z, Shukla D, Rajendran A, Pearson E, Stone EM, Zhang K, Pierce EA. 2007. The R345W mutation in EFEMP1 is pathogenic and causes AMD-like deposits in mice. Hum Mol Genet 16: 2411-2422.

Gorbatyuk MS, Knox T, LaVail MM, Gorbatyuk OS, Noorwez SM, Hauswirth WW, Lin JH, Muzyczka N, Lewin AS. 2010. Restoration of visual function in $\mathrm{P} 23 \mathrm{H}$ rhodopsin transgenic rats by gene delivery of BiP/Grp78. Proc Natl Acad Sci 107: 5961-5966.

Guo L, Salt TE, Luong V, Wood N, Cheung W, Maass A, Ferrari G, Russo-Marie F, Sillito AM, Cheetham ME, et al. 2007. Targeting amyloid- $\beta$ in glaucoma treatment. Proc Natl Acad Sci 104: 13444-13449.

Hardy J, Allsop D. 1991. Amyloid deposition as the central event in the aetiology of Alzheimer's disease. Trends Pharmacol Sci 12: 383-388.

Hargrave PA. 2001. Rhodopsin structure, function, and topography-the Friedenwald lecture. Invest Ophthalmol Vis Sci 42: 3-9.

Hebert DN, Molinari M. 2007. In and out of the ER: Protein folding, quality control, degradation, and related human diseases. Physiol Rev 87: 1377-1408.

Karan G, Yang Z, Zhang K. 2004. Expression of wild type and mutant ELOVL4 in cell culture: Subcellular localization and cell viability. Mol Vis 10: 248-253.

Karan G, Lillo C, Yang Z, Cameron DJ, Locke KG, Zhao Y, Thirumalaichary S, Li C, Birch DG, Vollmer-Snarr HR, et al. 2005a. Lipofuscin accumulation, abnormal electrophysiology, and photoreceptor degeneration in mutant ELOVL4 transgenic mice: A model for macular degeneration. Proc Natl Acad Sci 102: 4164-4169.

Karan G, Yang Z, Howes K, Zhao Y, Chen Y, Cameron DJ, Lin Y, Pearson E, Zhang K. 2005b. Loss of ER retention and sequestration of the wild-type ELOVL4 by Stargardt disease dominant negative mutants. Mol Vis 11: 657664.

Katz B, Rimmer S, Iragui V, Katzman R. 1989. Abnormal pattern electroretinogram in Alzheimer's disease: Evidence for retinal ganglion cell degeneration? Ann Neurol 26: $221-225$.

Kaushal S, Khorana HG. 1994. Structure and function in rhodopsin. 7. Point mutations associated with autosomal dominant retinitis pigmentosa. Biochemistry 33: 6121 6128.

Kaushal S, Ridge KD, Khorana HG. 1994. Structure and function in rhodopsin: The role of asparagine-linked glycosylation. Proc Natl Acad Sci 91: 4024-4028.

Krebs MP, Noorwez SM, Malhotra R, Kaushal S. 2004. Quality control of integral membrane proteins. Trends Biochem Sci 29: 648-655.

Krebs MP, Holden DC, Joshi P, Clark CLIII, Lee AH, Kaushal S. 2010. Molecular mechanisms of rhodopsin retinitis pigmentosa and the efficacy of pharmacological rescue. J Mol Biol 395: 1063-1078.

Leonard KC, Petrin D, Coupland SG, Baker AN, Leonard BC, LaCasse EC, Hauswirth WW, Korneluk RG, Tsilfidis C. 2007. XIAP protection of photoreceptors in animal models of retinitis pigmentosa. PLoS One 2: e314.

Lin JH, Li H, Yasumura D, Cohen HR, Zhang C, Panning B, Shokat KM, Lavail MM, Walter P. 2007. IRE1 signaling affects cell fate during the unfolded protein response. Science 318: 944-949.

Marmorstein AD, Marmorstein LY, Rayborn M, Wang X, Hollyfield JG, Petrukhin K. 2000. Bestrophin, the product of the Best vitelliform macular dystrophy gene (VMD2), localizes to the basolateral plasma membrane of the retinal pigment epithelium. Proc Natl Acad Sci 97: $12758-12763$.

Marmorstein LY, McLaughlin PJ, Peachey NS, Sasaki T, Marmorstein AD. 2007. Formation and progression of sSub-retinal pigment epithelium deposits in efempl mutation knock-in mice: A model for the early pathogenic course of macular degeneration. Hum Mol Genet 16: $2423-2432$.

Mata NL, Tzekov RT, Liu X, Weng J, Birch DG, Travis GH. 2001. Delayed dark-adaptation and lipofuscin accumulation in abcr ${ }^{+/}$mice: Implications for involvement of ABCR in age-related macular degeneration. Invest Ophthalmol Vis Sci 42: 1685-1690.

Mendes HF, van der Spuy J, Chapple JP, Cheetham ME. 2005. Mechanisms of cell death in rhodopsin retinitis pigmentosa: Implications for therapy. Trends $\mathrm{Mol} \mathrm{Med}$ 11: $177-185$.

Mendes CS, Levet C, Chatelain G, Dourlen P, Fouillet A, Dichtel-Danjoy ML, Gambis A, Ryoo HD, Steller H, Mollereau B. 2009. ER stress protects from retinal degeneration. EMBO J 28: 1296-1307.

Michaelides M, Johnson S, Poulson A, Bradshaw K, Bellmann C, Hunt DM, Moore AT. 2003. An autosomal dominant bull's-eye macular dystrophy (MCDR2) that maps to the short arm of chromosome 4. Invest Ophthalmol Vis Sci 44: 1657-1662.

Milenkovic VM, Rivera A, Horling F, Weber BH. 2007. Insertion and topology of normal and mutant bestrophin- 1 in the endoplasmic reticulum membrane. J Biol Chem 282: 1313-1321.

Morimoto T, Fujikado T, Choi JS, Kanda H, Miyoshi T, Fukuda Y, Tano Y. 2007. Transcorneal electrical stimulation promotes the survival of photoreceptors and preserves retinal function in royal college of surgeons rats. Invest Ophthalmol Vis Sci 48: 4725-4732.

Moritz OL, Tam BM. 2010. Recent insights into the mechanisms underlying light-dependent retinal degeneration from x. Laevis models of retinitis pigmentosa. Adv Exp Med Biol 664: 509-515.

Nathans J, Davenport CM, Maumenee IH, Lewis RA, Hejtmancik JF, Litt M, Lovrien E, Weleber R, Bachynski B, Zwas F. 1989. Molecular genetics of human blue cone monochromacy. Science 245: 831-838.

Noorwez SM, Kuksa V, Imanishi Y, Zhu L, Filipek S, Palczewski K, Kaushal S. 2003. Pharmacological chaperone-mediated in vivo folding and stabilization of the $\mathrm{P} 23 \mathrm{H}-$ opsin mutant associated with autosomal dominant retinitis pigmentosa. J Biol Chem 278: $14442-$ 14450.

Noorwez SM, Malhotra R, McDowell JH, Smith KA, Krebs MP, Kaushal S. 2004. Retinoids assist the cellular folding of the autosomal dominant retinitis pigmentosa opsin mutant P23H. J Biol Chem 279: 16278-16284.

Noorwez SM, Sama RR, Kaushal S. 2009. Calnexin improves the folding efficiency of mutant rhodopsin in 
R. Tzekov et al.

the presence of pharmacological chaperone 11-cis-retinal. J Biol Chem 284: 33333-333342.

Paquet C, Boissonnot M, Roger F, Dighiero P, Gil R, Hugon J. 2007. Abnormal retinal thickness in patients with mild cognitive impairment and Alzheimer's disease. Neurosci Lett 420: 97-99.

Parisi V, Restuccia R, Fattapposta F, Mina C, Bucci MG, Pierelli F. 2001. Morphological and functional retinal impairment in Alzheimer's disease patients. Clin Neurophysio 112: $1860-1867$.

Prager TC, Schweitzer FC, Peacock LW, Garcia CA. 1993. The effect of optical defocus on the pattern electroretinogram in normal subjects and patients with Alzheimer's disease. Am J Ophthalmol 116: 363-369.

Roy K, Stein L, Kaushal S. 2010. Ocular gene therapy: An evaluation of recombinant adeno-associated virusmediated gene therapy interventions for the treatment of ocular disease. Hum Gene Ther 21: 1-13.

Roybal CN, Marmorstein LY, Vander Jagt DL, Abcouwer SF 2005. Aberrant accumulation of fibulin-3 in the endoplasmic reticulum leads to activation of the unfolded protein response and VEGF expression. Invest Ophthalmol Vis Sci 46: 3973-3979.

Sartucci F, Borghetti D, Bocci T, Murri L, Orsini P, Porciatt V, Origlia N, Domenici L. 2010. Dysfunction of the magnocellular stream in Alzheimer's disease evaluated by pattern electroretinograms and visual evoked potentials. Brain Res Bull 82: 169-176.

Sauer CG, Gehrig A, Warneke-Wittstock R, Marquardt A Ewing CC, Gibson A, Lorenz B, Jurklies B, Weber BH. 1997. Positional cloning of the gene associated with X-linked juvenile retinoschisis. Nat Genet 17: 164-170.

Schröder M, Kaufman RJ. 2005. The mammalian unfolded protein response. Annu Rev Biochem 74: 739-789.

Schulz JB. 2007. Mechanisms of neurodegeneration in idiopathic Parkinson's disease. Parkinsonism Relat D 13 (Suppl 3): S306-S308.

Shinohara T, Mulhern ML, Madson CJ. 2008. Silencing gene therapy for mutant membrane, secretory, and lipid proteins in retinitis pigmentosa (RP). Med Hypotheses 70: 378-380.

Sohocki MM, Daiger SP, Bowne SJ, Rodriquez JA, Northrup H, Heckenlively JR, Birch DG, Mintz-Hittner H, Ruiz RS Lewis RA, et al. 2001. Prevalence of mutations causing retinitis pigmentosa and other inherited retinopathies. Hum Mutat 17: 42-51.

Stone EM, Lotery AJ, Munier FL, Héon E, Piguet B, Guymer RH, Vandenburgh K, Cousin P, Nishimura D, Swiderski RE, et al. 1999. A single EFEMP1 mutation associated with both Malattia Leventinese and Doyne honeycomb retinal dystrophy. Nat Genet 22: 199-202.
Strenn K, Dal-Bianco P, Weghaupt H, Koch G, Vass C, Gottlob I. 1991. Pattern electroretinogram and luminance electroretinogram in Alzheimer's disease. J Neural Transm Suppl 33: 73-80.

Surgechev A, Surgechev A. 2010. Conformational diseases: Looking into the eyes. Brain Res Bull 81: 12-24.

Szegezdi E, Logue SE, Gorman AM, Samali A. 2006. Mediators of endoplasmic reticulum stress-induced apoptosis. EMBO Rep 7: 880-885.

Tam BM, Moritz OL. 2006. Characterization of rhodopsin $\mathrm{P} 23 \mathrm{H}$-induced retinal degeneration in a Xenopus laevis model of retinitis pigmentosa. Invest Ophthalmol Vis Sci 47: 3234-3241.

Trick GL, Barris MC, Bickler-Bluth M. 1989. Abnormal pattern electroretinograms in patients with senile dementia of the Alzheimer type. Ann Neurol 26: 226-231.

Wang X, Nookala S, Narayanan C, Giorgianni F, BeranovaGiorgianni S, McCollum G, Gerling I, Penn JS, Jablonski MM. 2009. Proteomic analysis of the retina: Removal of RPE alters outer segment assembly and retinal protein expression. Glia 57: 380-392.

Weng J, Mata NL, Azarian SM, Tzekov RT, Birch DG, Travis GH. 1999. Insights into the function of Rim protein in photoreceptors and etiology of Stargardt's disease from the phenotype in abcr knockout mice. Cell 98: 13-23.

Wiszniewski W, Zaremba CM, Yatsenko AN, Jamrich M, Wensel TG, Lewis RA, Lupski JR. 2005. ABCA4 mutations causing mislocalization are found frequently in patients with severe retinal dystrophies. Hum Mol Genet 14: $2769-2778$.

Wu WW, Molday RS. 2003. Defective discoidin domain structure, subunit assembly, and endoplasmic reticulum processing of retinoschisin are primary mechanisms responsible for X-linked retinoschisis. J Biol Chem 278: 28139-28146.

Yang LP, Wu LM, Guo XJ, Tso MO. 2007. Activation of endoplasmic reticulum stress in degenerating photoreceptors of the rd1 mouse. Invest Ophthalmol Vis Sci 48: 5191-5198.

Yang Z, Chen Y, Lillo C, Chien J, Yu Z, Michaelides M, Klein M, Howes KA, Li Y, Kaminoh Y, et al. 2008. Mutant prominin 1 found in patients with macular degeneration disrupts photoreceptor disk morphogenesis in mice. J Clin Invest 118: 2908-2916.

Young RW. 1971. The renewal of rod and cone outer segments in the rhesus monkey. J Cell Biol 1: 303-318.

Zhang K, Kniazeva M, Han M, Li W, Yu Z, Yang Z, Li Y, Metzker ML, Allikmets R, Zack DJ, et al. 2001. A 5-bp deletion in ELOVL4 is associated with two related forms of autosomal dominant macular dystrophy. Nat Genet 27: $89-93$. 


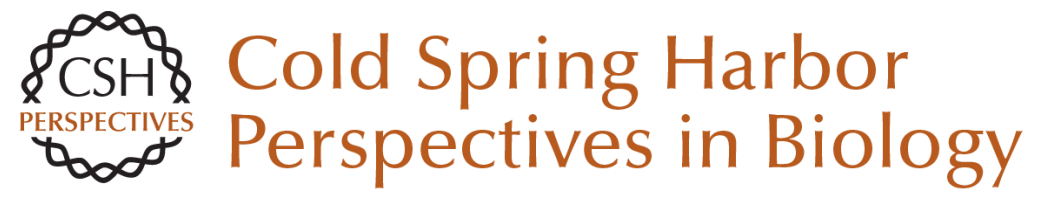

\section{Protein Misfolding and Retinal Degeneration}

Radouil Tzekov, Linda Stein and Shalesh Kaushal

Cold Spring Harb Perspect Biol 2011; doi: 10.1101/cshperspect.a007492 originally published online August 8, 2011

\section{Subject Collection Protein Homeostasis}

Proteome-Scale Mapping of Perturbed Proteostasis in Living Cells

Isabel Lam, Erinc Hallacli and Vikram Khurana

Pharmacologic Approaches for Adapting Proteostasis in the Secretory Pathway to Ameliorate Protein Conformational Diseases Jeffery W. Kelly

Cell-Nonautonomous Regulation of Proteostasis in Aging and Disease

Richard I. Morimoto

The Autophagy Lysosomal Pathway and Neurodegeneration Steven Finkbeiner

Functional Modules of the Proteostasis Network Gopal G. Jayaraj, Mark S. Hipp and F. Ulrich Hartl

Protein Solubility Predictions Using the CamSol Method in the Study of Protein Homeostasis Pietro Sormanni and Michele Vendruscolo

Recognition and Degradation of Mislocalized Proteins in Health and Disease

Ramanujan S. Hegde and Eszter Zavodszky

The Nuclear and DNA-Associated Molecular Chaperone Network

Zlata Gvozdenov, Janhavi Kolhe and Brian C. Freeman
The Amyloid Phenomenon and Its Significance in Biology and Medicine

Christopher M. Dobson, Tuomas P.J. Knowles and Michele Vendruscolo

A Chemical Biology Approach to the Chaperome in Cancer--HSP9O and Beyond

Tony Taldone, Tai Wang, Anna Rodina, et al.

Proteostasis in Viral Infection: Unfolding the Complex Virus-Chaperone Interplay Ranen Aviner and Judith Frydman

The Proteasome and Its Network: Engineering for Adaptability Daniel Finley and Miguel A. Prado

Functional Amyloids Daniel Otzen and Roland Riek

Chaperone Interactions at the Ribosome Elke Deuerling, Martin Gamerdinger and Stefan G. Kreft

Mechanisms of Small Heat Shock Proteins Maria K. Janowska, Hannah E.R. Baughman, Christopher N. Woods, et al.

Structure, Function, and Regulation of the Hsp90 Machinery

Maximilian M. Biebl and Johannes Buchner

For additional articles in this collection, see http://cshperspectives.cshlp.org/cgi/collection/

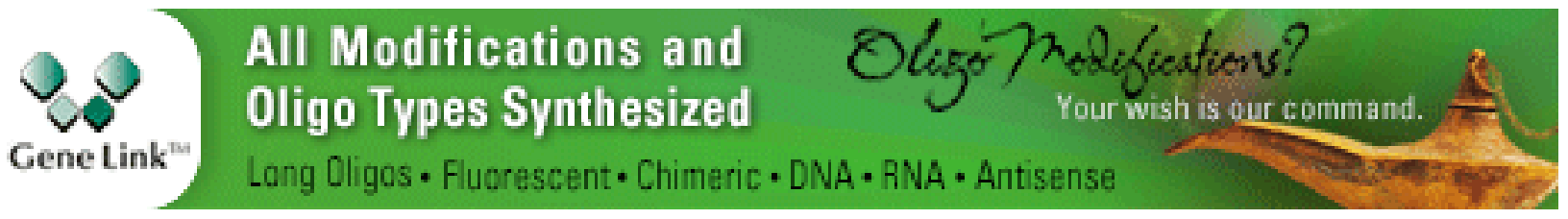


For additional articles in this collection, see http://cshperspectives.cshlp.org/cgi/collection/

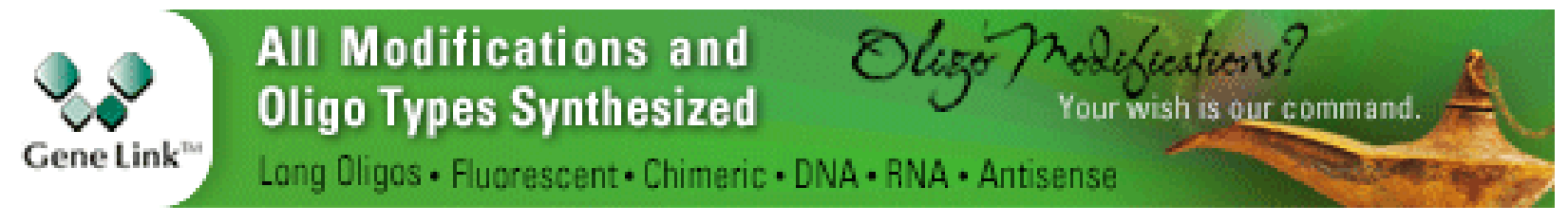

Copyright @ 2011 Cold Spring Harbor Laboratory Press; all rights reserved 